\title{
Benchmarking Organisational and Operational Development
}

\author{
A. Salminen, H. Lanning, J.-E. Tarpila, M. Roiha and M. Lahti \\ Helsinki University of Technology \\ TAI Research Centre \\ P.O. BOX 9555, FIN-02015 TKK \\ Tel: +358-9-451 4762, Fax: +358-9-4513665 \\ Email:antti.salminen@hut.fi, harri.lanning@hut.fi, \\ jan-erik.tarpila@hut.fi,mikko.roiha@hut.fi,mika.lahti@cern.ch
}

\section{Abstract}

This paper presents the success factors of multi-company benchmarking as a means of improving internal development methods and logistical structures in industrial companies.

Companies with interest on improving their development practices and operational performance through learning from others and sharing their knowledge were arranged as a benchmarking group coordinated by independent researchers of Helsinki University of Technology. The secondary aim of this paper is to describe how this has been carried out in different research project groups.

The experiences show that benchmarking method is an applicable and an effective tool as long as certain prerequisites are fulfilled and proper actions are taken to ensure that the critical success factors are taken into account in the implementation. Main findings are that similar responsibilities and tasks of participants, constant group composition, selection of topics, clear focus and concrete subjects, understanding the member organisations, thorough preparations, experienced chairman, quantitative analysis and members' case presentations are the main enablers for successful multi-company benchmarking of business process and logistics development.

\section{KEYWORDS}

benchmarking, organisational development, success factors 


\section{INTRODUCTION}

When organisational development and operational improvements are carried out in industrial enterprises, the means required include both general development methods and methods specific to the case. Even though company specific factors and features play an important role in development there still seem to be some general factors common to most development projects and programmes or improvement activities taken on some specific field of operations such as logistics. Using benchmarking as a method to transfer best development practices and operational solutions from one company to a group of others is based on the assumption that such common factors do exist and that it is possible to creatively adapt them to different operating environments and organisations.

According to Watson (1993) benchmarking is a systematic and continuous process where business processes are compared with other leading processes anywhere in the world. Process view, systematic measurement of the processes and continuous development are essential in defining benchmarking.

The method presented in this paper, although it does not fulfil the strictest conditions suggested for benchmarking, uses the logic behind it. Thus the method can be considered as an adaptation of process benchmarking to the field of organisational and operational development.

This paper is based on three benchmarking programmes where people responsible for development actions in their organisations were brought together to systematically exchange information about managing and implementing development, to compare the state of their operations and development activities on basis on the analysis and to locate the best practices. In addition, new effective and applicable solutions for a better performance were also discussed.

Each of the benchmarking programmes was carried out as a part of a wider research project including also development activities in individual companies. The benchmarking approach was used both to systematically and continuously develop the operations of participating companies and to develop deep general knowledge about the best practices on these issues.

Multi-company approach has some advantages compared to benchmarking only one company against another. Firstly, since a company can take advantage of the work executed in all other participating companies, it enables more efficient use of existing information. Secondly, it also provides a forum for a more profound benchmarking than other methods. The third advantage is synergy, that is where the knowledge of the companies is summarised, new knowledge is born (Jahnukainen et al., 1995).

\section{APPLIED BENCHMARKING METHOD}

All three benchmarking programmes were conducted in a similar way. Researchers at Helsinki University of Technology acted as coordinators in all programmes. The role of a coordinator in benchmarking sessions is significant as he is responsible for organising the programme itself, reacting to the specific needs of the 
participants, facilitating open sharing of knowledge and continuously improving the benchmarking method itself.

The programmes were based on a set of meetings in which one topic was handled at a time. The structure and content of the programme were discussed and agreed on during the first meetings. The rules of the benchmarking programme were also agreed on, which meant a mutual understanding of the confidentiality concerning the information shared during meetings. Even though the participating companies were not rivalries it was essential to discuss about trust and the rules of the game. One important topic to talk about was the commitment to the programme. Participants were not only responsible for themselves but also for other participants to put their best effort into helping everybody to make most of all meetings.

Company and project presentations were held in order to find out common interest areas and to give an overall picture of the participating companies and their development activities. Along the programmes the participants were able to have a deeper look into the structures, solutions and problems of each company in practice as each company hosted one meeting. Well arranged company visits were an effective way to disseminate best practices.

In addition to analysis, both quantitative and qualitative, subjective descriptions were also made about all organisations and used as a basis of benchmarking. Analyses were either made by coordinators or companies themselves depending on the nature and complexity of the analysis.

Participants were given thorough instructions on how to prepare for each session, which analysis to conduct, what sort of cases to present and what readings to go through in order to have sufficient understanding in the theoretical background of the days' topic. The meetings themselves had a certain constant pattern and agenda.

Some factors are crucial for a successful benchmarking programme. These prerequisites were identified and applied in all programmes. Successful benchmarking preconceives that all these prerequisites are fulfilled (Jahnukainen et al., 1995).

- Participating companies should not be direct competitors in order to enable active and open discussion and willingness to co-operate and share information with others.

- In the beginning of the programmes it was ensured that companies did indeed have similar interests as well as same kind of problems. A similar operation mode assures similar development needs. Especially in programmes $\mathrm{B}$ and $\mathrm{C}$ the similar operation mode, that is converging versus diverging logistics, is of great importance.

- A third prerequisite, willingness to develop and participate, is also a crucial factor as otherwise benchmarking easily turns into a set of meetings that only disturbs other responsibilities. Willingness was ensured by personal discussions with all candidates. This prerequisite is not tied up with the companies but with the persons who represent the company. 


\section{BENCHMARKING PROGRAMMES}

Even though all benchmarking programmes had different objectives and focus they had also many similarities. In addition, the programmes were conducted in a similar way all programmes had a multi-company attendance.

\subsection{Programme A: Benchmarking Change Projects}

The main objective of the benchmarking programme $\mathrm{A}$ was to find out best practices and main problems in internal development of business processes and operations through change projects. The assumption was that there are some generic factors crucial for all kinds of organisational and operational change projects (Lanning and Salminen, 1997). All participants of programme A were leading a change project within their own organisation with work assignments ranging from the project manager to the technical manager. The companies represented different industries with different operating modes ranging from building services to the pharmaceutical industry.

The programme was divided into eight benchmarking meetings that were held during a period of about ten months. In each meeting one topic was handled systematically to find out good examples, cases, best practices and biggest problems around that particular topic area.

\subsection{Programme B: Developing Logistics of Make-to-Order Companies within Metal Industry}

Members of the second programme group came from different fields of the Finnish metal industry. Companies were acting on global markets on a make-to-order basis. Supply chains were monitored and measured to find out the particular characteristics of the project group companies' delivery chains. The best practices were located on the basis of these comparisons.

During the 15-month project, eight project meetings were arranged. The focus in the meetings was on process management, product management, order processing and purchasing. In these meetings companies presented the analysis results and discussed them.

\subsection{Programme C: Developing Logistics of Food Industry}

The benchmarking programme three is still ongoing, so all the observations from it are preliminary in nature. All companies in programme $\mathrm{C}$ are major Finnish producers of food and beverages. Companies operate mainly in the Nordic Countries with focus on Finnish markets the majority being market leaders in Finland. The main objective of programme $\mathrm{C}$ is to find best practices within delivery chain logistics in order to simultaneously maximise customer satisfaction and operating profits.

Eight meetings are arranged during 26 months. The structure of these meetings is very similar to programme $B$. The focus in the meetings was on information exchange and logistical structures affecting delivery times in food industry. 


\subsection{Comparing the programmes}

Some aspects describing the structures of the three benchmarking programmes are presented in the Table 1. Noticeable is that the three benchmarking programmes differ in many ways. Participants in the different programmes come from different fields of industries, act in different operational areas or represent different organisational levels. All programmes had different objectives and focus, and consequently, also the level of discussion as well as the level of confidentiality of matters discussed varied.

Table 1: Benchmarking programmes

\begin{tabular}{|c|c|c|c|}
\hline Programme & $A$ & $B$ & C \\
\hline Objective of programme & change projects & $\begin{array}{l}\text { developing } \\
\text { converging } \\
\text { logistics }\end{array}$ & $\begin{array}{l}\text { developing } \\
\text { diverging } \\
\text { logistics }\end{array}$ \\
\hline \# of companies & 8 & 7 & 8 \\
\hline \# of sessions & 8 & 8 & 8 \\
\hline \# of participants & $10 /$ meeting & $15-20 /$ meeting & $20-30 /$ meeting \\
\hline Last meeting/duration & 1997/1year & $1995 / 1,5$ years & $1999 / 2$ years \\
\hline Participants' position & varying & managerial & managerial \\
\hline $\begin{array}{l}\text { Standardisation of } \\
\text { agenda }\end{array}$ & high & low & low \\
\hline $\begin{array}{l}\text { Participants' } \\
\text { preunderstanding of } \\
\text { topics }\end{array}$ & $\begin{array}{l}\text { varying by } \\
\text { topic and } \\
\text { participant }\end{array}$ & good & good \\
\hline Mode of operations & varying & similar & similar \\
\hline Focus of programme & vast, general & focused & focused \\
\hline Field of industry & varying & same (metal) & same (food) \\
\hline Level of objectives & $\begin{array}{l}\text { concrete } \\
\text { solutions }\end{array}$ & $\begin{array}{c}\text { general } \\
\text { principles }\end{array}$ & $\begin{array}{c}\text { general } \\
\text { principles }\end{array}$ \\
\hline Level of discussion & operational & operational & strategic \\
\hline
\end{tabular}

\section{SUCCESS FACTORS OF BENCHMARKING PROGRAMMES}

The programmes were assessed in three ways. Action research methodology was used during the programme and feedback from the participants was collected through interviews and questionnaires. The method itself was continuously developed and improved during the programme.

Due to the structural similarities between the programmes, some enablers for successful benchmarking could be pointed out. Presuming that all member 
companies and participants could meet the prerequisites mentioned earlier, the most relevant success factors encountered during the programmes can be crystallised into following points.

- Similar responsibilities and tasks of participants ensure that everybody making the most of all meetings. Optimally, each company should send representatives from equal positions and they should have approximately similar values, similar task-orientation and high motivation to ensure interactive change of knowledge.

- Constant group composition strengthens the feeling of togetherness and also encourages mutual trust and openness as well as open discussion. The programme must have high enough priority so that participants have time to participate in most of the meetings.

- Selection of topics is crucial for successful meetings. Topics should be such that the best practices on issues critical for the long term success of the member companies can be found among them. It is also important to find topics which the participants can directly affect.

- Clear focus and concrete subjects of each session guarantee that practical solutions to the acute problems of the member can be found. The challenge was to choose topics that are specific enough for one day discussion but at the same time give a holistic view of the chosen field of development during the limited number of the meetings.

- Understanding the member organisations' operations is crucial for the coordinating partner to be able to succeed with the previous four points and direct the discussion to the right issues. Furthermore, it helps to anticipate and avoid possible problems.

- Thorough preparations for the meetings by the participants safeguard that participants can contribute to the discussion as much as possible while concentrating on the issue.

- Experienced chairmanship can be the crucial factor for achieving unconstrained discussion during the meetings.

- Quantitative analysis made in the member organisations makes it possible to achieve tangible benchmarking results. Without concrete results the group of members would merely form an ordinary group of people loosely talking about a certain subject.

- Case presentations of the members make meetings interesting and motivating. In addition, it offers a possibility to constructively discuss about member organisations' specific problems.

In order to gain some understanding about general rules for applying the benchmarking approach used, experiences from the benchmarking programmes are assessed in Table 2 . The three benchmarking programmes differ in many ways, as presented in Chapter 3. The factors marked with X were seen as the most crucial success factors in each benchmarking programme. Also the other factors affected the success of these programmes, but were of minor importance. 
Table 2: Critical success factors in different benchmarking programmes

\begin{tabular}{|c|c|c|c|}
\hline Programme & $A$ & $B$ & $C$ \\
\hline Similar responsibilities and tasks of participants & $\mathrm{X}$ & & \\
\hline Constant group composition & & & $\mathrm{X}$ \\
\hline Selection of topics & & & $\mathrm{X}$ \\
\hline Clear focus and concrete subjects & $\mathrm{X}$ & & \\
\hline Understanding the member organisations & & $\mathrm{X}$ & $\mathrm{X}$ \\
\hline Thorough preparations & $\mathrm{X}$ & & \\
\hline Experienced chairman & & & $\mathrm{X}$ \\
\hline Quantitative analysis made in member organisations & & $\mathrm{X}$ & \\
\hline Members' own well prepared case presentations & $\mathrm{X}$ & $\mathrm{X}$ & \\
\hline
\end{tabular}

The differences in the relative weights of the success factors of the programmes are explained by the differences in the programmes themselves.

Similar responsibilities and tasks of participants were crucial to programme A because the companies didn't represent the same industry and the objectives of the programme were very concrete aiming at instant improvements. Thus working with same problems formed the common background required for the comparisons to be fruitful.

In programme $\mathrm{C}$ the issues discussed were of strategic level, which emphasised the meaning of confidentiality and trust between the participants. This was gained through constant composition of the group. In programme A some companies even sent a special representative with deeper knowledge on the issue handled to certain sessions.

Selection of topics was especially important in programme C mostly due to the strategic level of the discussions and the scope of the programme, which was quite precisely defined. On the other hand, a clear focus of each session was not so important to programmes $\mathrm{B}$ and $\mathrm{C}$, as the focus of the programme guaranteed sufficient restriction for the issues to be included in discussions. In programme A this was the other way round and also the concrete objectives required clear focus of each session.

The understanding of the member organisations was crucial to programmes $\mathrm{B}$ and $\mathrm{C}$ dealing with certain characteristics of the logistics of the companies. Coordinators as well as all the participants had to have a thorough knowledge of dynamics and performance of certain type of delivery chains. In programme A there was no need to know individual companies in such depth but rather the basics of business process development work in general.

Thorough preparations of each meeting seemed to have a special importance in programme $\mathrm{A}$ as it had concrete objectives and it aimed to immediately applicable 
solutions. Also the varying experience of participants and varying preunderstanding of the issues placed emphasis on the preparations.

Programme $\mathrm{C}$ had such a large group of participants that the role of the coordinators, especially the chairman, was very important. Also the strategic level of discussion and lack of well standardised agenda required experienced chairmanship.

In programme B the quantitative analysis conducted in all the companies was the most important success factor. This is due to the objectives of the programme: trying to locate and disseminate best practices on logistical issues on operational level. Using analysis results as the basis of discussions prevented the sessions from becoming merely "chatting clubs".

Members' own well-prepared case presentations formed the core of the programmes $\mathrm{A}$ and $\mathrm{B}$, but were not that crucial to programme $\mathrm{C}$. This is probably due to the operational level of discussions on the former two.

\section{CONCLUSIONS AND ISSUES FOR FURTHER RESEARCH}

It can be concluded that the applied multi-company bechmarking method introduced here is an effective means of locating and disseminating best practices in the field of organisational and operational development. However, to be successful the benchmarking programme should be planned according to certain principles taking in account the prerequisites and critical success factors.

In addition, the field of development activities, objectives of the programme, level of discussions and composition of the group seem to determine which of the success factors dominate and what kind of benefits are likely to be accomplished.

Further knowledge and experiences are needed about certain issues of multicompany benchmarking. First of all, how can such a benchmarking group be enhanced also to accomplish the continuous development aspect of benchmarking ideology? Secondly, what is needed to ensure that the located best practices are indeed put into practice by the participating companies.

\section{REFERENCES}

Jahnukainen J., Lahti M. and Luhtala M. (1995) LOGIPRO - Towards World Class Make-to-Order Supply Chains. Helsinki University of Technology, Industrial Economics and Industrial Psychology, Otaniemi

Lanning H. and Salminen A. (1997) A Step by Step Path for Implementing Change. Publications of IEMS 1997, International Conference on Industry, Engineering and Management Systems. 328-332.

Watson G. (1993) Strategic Benchmarking - How to Rate Your Company Against the Worlds Best. John Wiley \& Sons, New York 